\title{
IWATE criteria are associated with perioperative outcomes in robotic hepatectomy: a retrospective review of 225 resections
}

\author{
Kevin P. Labadie ${ }^{1}$. David J. Droullard ${ }^{1}$ - Alex W. Lois ${ }^{1}$. Sara K. Daniel ${ }^{1} \cdot$ Kathryn E. McNevin $^{1}$. \\ Jaqueline Valdez Gonzalez ${ }^{1}$. Yongwoo D. Seo ${ }^{1} \cdot$ Kevin M. Sullivan $^{1} \cdot$ Kyle S. Bilodeau $^{1} \cdot$ Lindsay K. Dickerson $^{1}$. \\ Alan F. Utria ${ }^{1} \cdot$ John Calhoun ${ }^{1} \cdot$ Venu G. Pillarisetty ${ }^{1,2,3} \cdot$ Jonathan G. Sham ${ }^{1,2,3} \cdot$ Raymond S. Yeung $^{1,2,3}$. \\ James O. Park ${ }^{1,2,3}$ (i)
}

Received: 19 September 2020 / Accepted: 27 January 2021 / Published online: 19 February 2021

(c) The Author(s) 2021

\begin{abstract}
Background Robotic hepatectomy (RH) is increasingly utilized for minor and major liver resections. The IWATE criteria were developed to classify minimally invasive liver resections by difficulty. The objective of this study was to apply the IWATE criteria in RH and to describe perioperative and oncologic outcomes of RH over the last decade at our institution. Methods Perioperative and oncologic outcomes of patients who underwent RH between 2011 and 2019 were retrospectively collected. The difficulty level of each operation was assessed using the IWATE criteria, and outcomes were compared at each level. Univariate linear regression was performed to characterize the relationship between IWATE criteria and perioperative outcomes (OR time, EBL, and LOS), and a multivariable model was also developed to address potential confounding by patient characteristics (age, sex, BMI, prior abdominal surgery, ASA class, and simultaneous non-hepatectomy operation). Results Two hundred and twenty-five RH were performed. Median IWATE criteria for RH were 6 (IQR 5-9), with low, intermediate, advanced, and expert resections accounting for $23 \%(n=51), 34 \%(n=77), 32 \%(n=72)$, and $11 \%(n=25)$ of resections, respectively. The majority of resections were parenchymal-sparing approaches, including anatomic segmentectomies and non-anatomic partial resections. 30-day complication rate was $14 \%$, conversion to open surgery occurred in 9 patients (4\%), and there were no deaths within 30 days postoperatively. In the univariate linear regression analysis, IWATE criteria were positively associated with OR time, EBL, and LOS. In the multivariable model, IWATE criteria were independently associated with greater OR time, EBL, and LOS. Two-year overall survival for hepatocellular carcinoma and intrahepatic cholangiocarcinoma was $94 \%$ and $50 \%$, respectively.

Conclusion In conclusion, the IWATE criteria are associated with surgical outcomes after RH. This series highlights the utility of RH for difficult hepatic resections, particularly parenchymal-sparing resections in the posterosuperior sector, extending the indication of minimally invasive hepatectomy in experienced hands and potentially offering select patients an alternative to open hepatectomy or other less definitive liver-directed treatment options.
\end{abstract}

Keywords Robotic hepatectomy $\cdot$ Minimally invasive surgery $\cdot$ IWATE criteria $\cdot$ Robotic surgery

James O. Park

jopark@uw.edu

1 Department of Surgery, University of Washington School of Medicine, 1959 NE Pacific Street, Health Sciences Bldg. Room BB-442, Box 356410, Seattle, WA 98195, USA

2 Center for Advanced Minimally Invasive Liver Oncologic Therapies (CAMILOT), University of Washington, Seattle, WA 98195, USA

3 Hepatobiliary Surgical Oncology, Department of Surgery, University of Washington Medical Center, 1959 NE Pacific Street, Health Sciences Bldg. Room BB-442, Box 356410, Seattle, WA 98195-6410, USA
Minimally invasive approaches for liver resection are increasingly utilized including laparoscopic and robotassisted laparoscopic techniques, or robotic hepatectomy (RH). Over the last two decades, numerous single and multiinstitutional case series report outcomes of $\mathrm{RH}$, demonstrating comparable outcomes to standard laparoscopic and open hepatectomy [1-5]. Initially reserved for minor resections in the lateral sector, accumulated experience, technological advancements, and improvements in perioperative care have enabled RH for complex hepatectomy in many high-volume centers [6-9]. RH has been suggested to be advantageous to 
standard laparoscopic hepatectomy for certain resections, such as resection of posterosuperior hepatic segments; however, prospective data are lacking and comparing techniques in liver resection is limited by challenges in controlling for the extent and difficulty of resection [10-12].

To better control for these factors, several hepatectomy difficulty scoring systems have been developed based on patient and tumor factors. The first difficulty scoring system was developed by Ban et al. and was validated for RH[4, 13]. However, there were several limitations to the initial iteration, including omission of resections in segment 1 , the inability to distinguish between a tumor in segment $4 \mathrm{~A}$ or 4B or account for hand-assisted or hybrid approaches. This prompted its revision to the IWATE criteria in 2014, composed of a 4-level classification system accounting for the tumor location, its size, and proximity to a major hepatic vessel, the extent of liver resection, the utilization of a hybrid technique, and the patient's liver function[14].

The aim of this study was to apply the IWATE criteria in RH and to characterize its association with perioperative outcomes, while reporting our initial institutional experience with RH over the last decade.

\section{Methods}

\section{Study design and population}

We performed a retrospective cohort study of all patients who underwent RH for primary hepatobiliary (PHB), metastatic, and benign liver tumors between 2011 and 2019 at the University of Washington Medical Center. Primary hepatobiliary (PHB) malignancies included hepatocellular carcinoma (HCC), intrahepatic cholangiocarcinoma (ICC), and gallbladder carcinoma (GBC). Diagnosis and treatment plans were made based on established criteria and guidelines from the National Comprehensive Cancer Network and other professional societies. All patients were evaluated by a multidisciplinary care team including experts from surgical, radiation, and medical oncology; transplant surgery and hepatology; diagnostic and interventional radiology; and pathology. The study protocol was approved by the Institutional Review Board and Human Subjects Research Division at the University of Washington.

\section{Operative technique and definitions}

Liver segments were identified based on Couinaud's segmental anatomic classification [15]. Anatomic resections were defined based on the Brisbane 2000 Terminology of Liver Anatomy and Resections [16]. Major liver resections were defined by resection of 3 or more adjoining Couinaud's segments. The term "parenchymal-sparing" encompassed anatomic segmentectomy and non-anatomic partial resection.

All patients underwent RH using the da Vinci Surgical System $^{\text {TM }}$ (Intuitive Surgical, Inc, Sunnyvale, CA) Xi or $\mathrm{Si}$ models. Both extrahepatic and intrahepatic control are used and selected based on patient's anatomy. Pringle maneuver was rarely used, and portal pedicles were controlled by extra or intrahepatic approach. Parenchymal transection was performed mainly with a Harmonic ${ }^{\mathrm{TM}}$ scalpel, with vascular control using Hem-o-lok ${ }^{\mathrm{TM}}$ clips or sutures, under ultrasound guidance using a drop-in probe. ICG fluorescence was occasionally used to identify planes of parenchymal resection. Operations were converted to an open approach when deemed necessary by the operating surgeon for management of prohibitive adhesive disease, hemorrhage, or failure to make timely progress. The primary robotic surgeons include authors JOP, RSY, VGP, and JGS. All cases were with a resident at bedside and rarely a second attending surgeon assisted at bedside or at surgeon console.

\section{Collected data}

Patient demographics and perioperative data for all $\mathrm{RH}$ patients were collected, while oncologic outcomes were collected for patients with PHB malignancies with at least 6 months of follow-up. Patient demographics and clinical characteristics included age, gender, body mass index (BMI), ASA class, prior abdominal operation, and presence of moderate or severe steatosis or cirrhosis identified on surgical pathology. Perioperative data including the number and location of hepatic segments resected, operative time, estimated blood loss (EBL), operative blood products transfused, 30-day complications, conversion to an open operation, and length of hospital stay were collected. Operations that included concomitant surgical procedures, e.g., concurrent colectomy, were excluded from operative time, EBL, blood transfusion, and length of stay univariate analyses but included in multivariable model. The operation type, number and location of hepatic segments resected, the tumor size, proximity to major vasculature, and patient's Childs Pugh score were collected, and the IWATE criteria were tabulated as described [14]. Segmentectomy was defined as a complete resection of an area supplied by a $3^{\text {rd }}$ order branch of the portal vein $[17,18]$. When a tumor involved more than one Couinaud segment, the segment which was more involved by tumor was used for tabulation. The IWATE criteria were utilized to categorize the RH as a low- (criteria $0-3$ ), intermediate- (criteria 4-6), advanced- (criteria 7-9), or expert-level (criteria 10-12) resection for analysis. 


\section{Oncologic outcomes}

Tumor characteristics including histologic subtype, tumor diameter, and resection margin status were collected from pathology reports for all resections. Oncologic outcomes, including disease-free survival and overall survival, were examined for PHB malignancies in patients with greater than 6 months of follow-up. Deaths were identified by EMR documentation, and disease recurrence was defined as documented tumor recurrence on surveillance computed tomography or magnetic resonance imaging. Based on these definitions, for patients with at least 2 years of follow-up care documented in the EMR, we calculated disease-free survival and overall survival at this time point. Assessing oncologic outcomes after resection of metastatic tumors was outside the scope of this work, as characteristics of the primary tumor and its systemic treatment more strongly influence survival than resection approach, and these data were not available. In addition, metastatic lesions are not routinely surveilled in our liver tumor clinic, and therefore, follow-up was limited.

\section{Statistical analysis}

Categorical variables were expressed as frequency and percentages and analyzed using Chi-square or Fisher's exact tests where appropriate. Continuous variables were expressed as medians and means and compared by Student's $t$ test or Mann-Whitney test depending on distribution of variables. To assess the relationship between IWATE score and OR time, EBL, and LOS, we first performed univariate linear regression with robust standard errors. To control for potential confounding by patient characteristics (age, sex, obesity, ASA class, prior abdominal operation, and simultaneous non-hepatectomy operation), we developed multivariable linear regression models using robust standard errors. Multivariable logistic regression was also performed to evaluate the association between IWATE criteria and 30-day postoperative complications. Results were considered significant with a $p$ value $<0.05$. Linear regression analysis was performed using Stata v. 16.0 (Stata Corp, College Station, TX, USA), categorical and continuous variables were compared in PRISM.

\section{Results}

\section{Perioperative outcomes}

Two hundred and twenty-five RH were performed at our institution during the study period with patient and resection characteristics as listed in Table 1 . The majority of resections were parenchymal-sparing approaches, including anatomic
Table 1 Clinical characteristics, patient demographics, and resection specifics

\begin{tabular}{|c|c|}
\hline Characteristics & $\begin{array}{l}\text { RH } \\
(n=225)\end{array}$ \\
\hline Age (yr), median (range) & $56(21-85)$ \\
\hline Gender, female, $n(\%)$ & $110(49)$ \\
\hline Body mass index, median (range) & $26(17-67)$ \\
\hline Prior abdominal surgery, $n(\%)$ & $140(62)$ \\
\hline \multicolumn{2}{|l|}{ ASA classification, $n(\%)$} \\
\hline 2 & 64 (28) \\
\hline 3 & $144(64)$ \\
\hline 4 & $9(1)$ \\
\hline Presence of moderate steatosis, $n(\%)$ & $52(23)$ \\
\hline \multicolumn{2}{|l|}{ Indication, $n(\%)$} \\
\hline PHB Malignancy & $92(41)$ \\
\hline $\mathrm{HCC}$ & $68(30)$ \\
\hline ICC & $17(8)$ \\
\hline GBC & $7(3)$ \\
\hline Metastatic disease & $98(44)$ \\
\hline Benign/other & $34(15)$ \\
\hline Major resection, $n(\%)$ & $57(25 \%)$ \\
\hline \multicolumn{2}{|l|}{ Type of resection, $n(\%)$} \\
\hline Anatomic resection & $148(66)$ \\
\hline Left-lateral sectionectomy & $21(6)$ \\
\hline Left hepatectomy & $9(4)$ \\
\hline Right hepatectomy & $15(7)$ \\
\hline Extended left lobectomy & $1(<1)$ \\
\hline Extended right lobectomy & $2(<1)$ \\
\hline Segmentectomy, $n(\%)$ & $100(43)$ \\
\hline Non-anatomic resection, $n(\%)$ & $77(34)$ \\
\hline Tumor diameter $(\mathrm{cm})$, mean $\pm \mathrm{SD}$, maximum diameter & $3.6 \pm 2.5,15$ \\
\hline \multicolumn{2}{|l|}{ Hepatic segments involved by resected tumor $(n)$} \\
\hline 1 & 8 \\
\hline 2 & 55 \\
\hline 3 & 77 \\
\hline $4 \mathrm{~A}$ & 29 \\
\hline $4 \mathrm{~B}$ & 48 \\
\hline 5 & 81 \\
\hline 6 & 72 \\
\hline 7 & 51 \\
\hline 8 & 51 \\
\hline
\end{tabular}

segmentectomies and non-anatomic partial resections. The median IWATE criteria for RH were 6 (IQR 5-9), with low, intermediate, advanced, and expert resections accounting for $23 \%(n=51), 34 \%(n=77), 32 \%(n=72)$, and $11 \%(n=25)$ of resections, respectively (Table 2 ).

Conversion to open hepatectomy occurred in 9 patients (4\%), seven of them during advanced- or expert-level cases (IWATE criteria $\geq 7$ ). Four conversions occurred for hemorrhage control (IWATE criteria: 1 intermediate, 2 advanced, 
Table 2 Operative characteristics and perioperative outcomes by IWATE criteria

\begin{tabular}{lllll}
\hline IWATE criteria & Low & Intermediate & Advanced & Expert \\
\hline Number of resections & 51 & 77 & 72 & 25 \\
Partial resection, $n$ & 52 & 25 & 0 & 0 \\
Left-lateral sectionectomy, $n$ & 0 & 21 & 1 & 0 \\
Segmentectomy, $n$ & 0 & 30 & 57 & 14 \\
Sectionectomy and more & 0 & 0 & $338(184-863)$ & $800(300-1600)$ \\
Estimated blood loss (mL), median (IQR) & $100(50-150)$ & $200(80-400)$ & $330(260-390)$ & $400(296-470)$ \\
Operative time (min), median (IQR) & $216(159-272)$ & $230(188-296)$ & $3(2-4)$ & $4(2.25-4.75)$ \\
Length of hospital stay (day), median (IQR) & $2(2-3)$ & $3(2-3)$ & $3(4)$ & $4(15)$ \\
Conversion to open surgery, $n(\%)$ & 0 & $2(1)$ & 14 & 28 \\
Complication rate (\%) & 14 & 10 & 1 & 0 \\
Clavien-Dindo Grade $1, n$ & 1 & 2 & 8 & 4 \\
Clavien-Dindo Grade $2, n$ & 4 & 5 & 1 & 3 \\
Clavien-Dindo Grade 3, $n$ & 1 & 1 & 0 & 0 \\
Clavien-Dindo Grade $4, n$ & 1 & 0 & 86 & 80 \\
R0 resection (\%) & 93 & 85 & \\
\hline
\end{tabular}

1 expert), two for extensive adhesions (IWATE criteria: 2 expert), two for failure to progress (IWATE criteria: 1 advanced, 1 expert), and one for diaphragmatic involvement (IWATE criteria: 1 intermediate). Postoperative complications occurred within the first 30 days in 32 patients (14\%) with most common being superficial and deep surgical site infection $(n=7,3 \%)$, atrial fibrillation $(n=4,2 \%)$, and pulmonary embolism $(n=3,1 \%)$. The majority $(n=17,53 \%)$ of complications within 30-days occurred after advanced or expert-level resections (IWATE criteria $\geq 7$ ). The median length of stay was 3 days (IQR 2-4), and there were no deaths within 30 days postoperatively.

Of the $25 \mathrm{RH}$ categorized as expert-level resections, 10 right hepatectomies ( $\mathrm{rH}), 2$ extended right hepatectomies (erH), and 13 posterosuperior segmentectomies (psS) were performed. They were most commonly performed for metastatic tumors $(n=12)$ and HCC $(n=9)$, and the majority occurred in the second half of the study period $(n=16)$. Sixteen percent $(n=4)$ of expert-level resections were converted to open surgery ( 2 for adhesive disease for erH, 1 for hemorrhage control for $\mathrm{psS}, 1$ for failure to progress for psS). Twenty eight percent $(n=7)$ had postoperative complications (seroma, biloma, small bowel obstruction, pneumothorax, aspiration pneumonia, intra-abdominal abscess requiring percutaneous drainage). The expert-level segmentectomies were performed for large tumors (mean tumor size $5.1 \mathrm{~cm}$ ) in segment $4 \mathrm{~A}, 7$, and 8 with median EBL of $1320 \mathrm{~mL}$, median OR time of $406 \mathrm{~min}$, complication rate of $23 \%$, and $\mathrm{R} 0$ resection rate of $70 \%$.

In the univariate linear regression analysis, IWATE criteria were positively associated with OR time, EBL, and LOS (Figs. 1, 2, 3). In the multivariable model, IWATE criteria were independently associated with greater OR

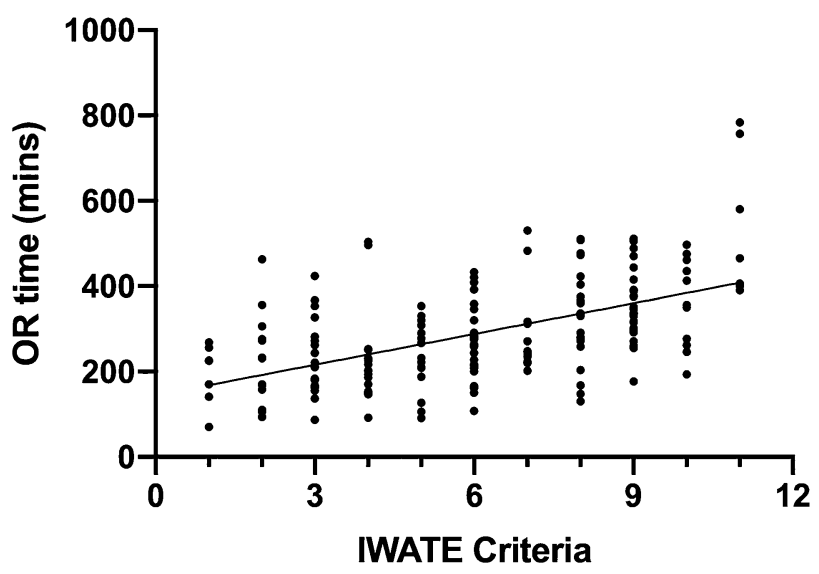

Fig. 1 Correlation of IWATE criteria with operative time $\left(R^{2}=0.30\right.$, $p<0.001)$

time, EBL, and LOS (Tables 3, 4, 5). We estimate that each additional IWATE criterion was associated with a 24 min greater mean OR time (95\% CI 18-30 min, $p<0.0005), 110$ cc greater mean EBL (95\% CI 81-139 cc, $p<0.0005)$, and 0.22 days greater mean $\operatorname{LOS}(95 \% \mathrm{CI}$ $0.13,0.31, p<0.0005)$. Combined cases were independently associated with greater OR time and length of stay but not EBL; none of the other patient characteristics were independently associated with these outcomes. IWATE criteria were not associated with an increase in 30-day complication rate (OR 1.10, 95\% CI 0.95-1.27, $p=0.19$ ).

\section{Oncologic outcomes}

Eighty-four patients who underwent RH for a PHB malignancy (63 HCC, 14 ICC, 7 GBC) had sufficient follow-up 


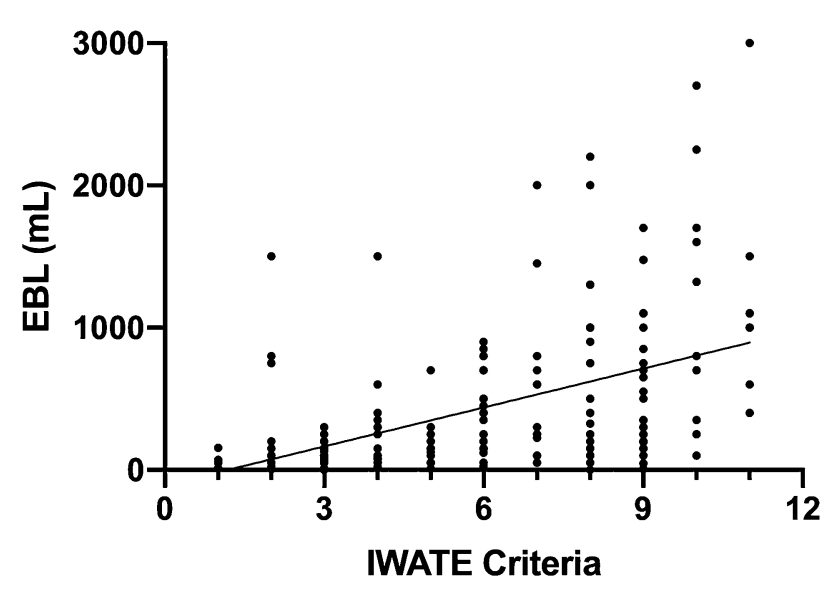

Fig. 2 Correlation of IWATE criteria with estimated intraoperative blood loss $\left(R^{2}=0.22, p<0.001\right)$

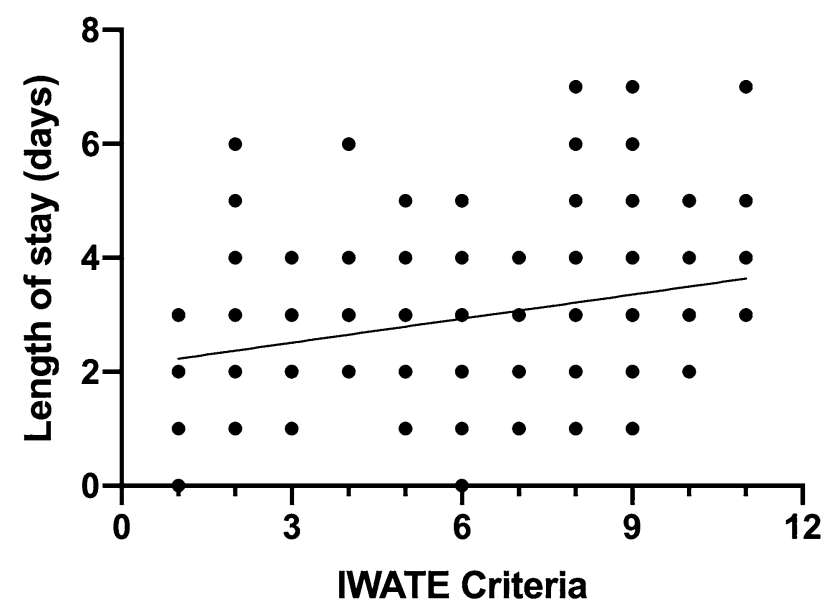

Fig. 3 Correlation of IWATE criteria with postoperative length of hospital stay $\left(R^{2}=0.08, p<0.001\right)$

Table 3 Relationship between IWATE criteria and OR Time (minutes)

\begin{tabular}{lrrrl}
\hline Independent Variable & Coefficient & $95 \%$ CI & \multicolumn{2}{l}{$p$} \\
\hline IWATE Criteria & 23.67 & 17.78 & 29.56 & $<0.0005$ \\
Age & -1.22 & -2.49 & 0.06 & 0.061 \\
Female sex & 14.28 & -18.94 & 47.51 & 0.398 \\
Obesity & 2.04 & -33.26 & 37.33 & 0.91 \\
Prior Abdominal Surgery & 7.63 & -26.35 & 41.61 & 0.659 \\
ASA Class & 12.54 & -15.28 & 40.36 & 0.375 \\
Combined Case & 185.26 & 142.90 & 227.63 & $<0.0005$ \\
Constant & 171.24 & 67.92 & 274.55 & 0.001 \\
\hline
\end{tabular}

$R^{2}=0.387$
Table 4 Relationship between IWATE criteria and EBL (cc)

\begin{tabular}{lrrrc}
\hline Independent variable & Coefficient & \multicolumn{1}{l}{$95 \%$ CI } & \multicolumn{2}{c}{$p$} \\
\hline IWATE Criteria & 109.57 & 80.58 & 138.55 & $<0.0005$ \\
Age & -3.08 & -9.40 & 3.23 & 0.34 \\
Female sex & -184.62 & -348.61 & -20.62 & 0.03 \\
Obesity & 65.41 & -108.31 & 239.12 & 0.46 \\
Prior Abdominal & 59.43 & -108.47 & 227.33 & 0.49 \\
$\quad$ Surgery & & & & \\
ASA class & 47.09 & -88.27 & 182.45 & 0.49 \\
Combined case & 20.71 & -183.24 & 224.66 & 0.84 \\
Constant & -80.65 & -586.20 & 424.90 & 0.75 \\
\hline$R^{2}=0.231$ & & & &
\end{tabular}

Table 5 Relationship between IWATE criteria and LOS (days)

\begin{tabular}{lrrrl}
\hline Independent variable & Coefficient & $95 \%$ CI & \multicolumn{1}{l}{$p$} \\
\hline IWATE Criteria & 0.219 & 0.131 & 0.307 & $<0.0005$ \\
Age & 0.011 & -0.008 & 0.031 & 0.244 \\
Female sex & -0.027 & -0.527 & 0.472 & 0.915 \\
Obesity & 0.026 & -0.502 & 0.553 & 0.924 \\
Prior abdominal surgery & 0.173 & -0.339 & 0.684 & 0.506 \\
ASA class & 0.340 & -0.072 & 0.752 & 0.105 \\
Combined case & 1.825 & 1.202 & 2.448 & $<0.0005$ \\
Constant & 0.091 & -1.447 & 1.629 & 0.907 \\
\hline
\end{tabular}

$R^{2}=0.203$

Table 6 Oncologic outcomes

\begin{tabular}{llll}
\hline & $\begin{array}{l}\mathrm{HCC} \\
(\mathrm{n}=63)\end{array}$ & $\begin{array}{l}\mathrm{ICC} \\
(\mathrm{n}=14)\end{array}$ & $\begin{array}{l}\text { GBC } \\
(\mathrm{n}=7)\end{array}$ \\
\hline $\begin{array}{l}\text { Largest tumor diameter (cm), } \\
\text { median (range) }\end{array}$ & $4.1(1-12)$ & $4.1(2-7)$ & $2.2(0.1-6)$ \\
$\begin{array}{l}\text { R0 resection, n (\%) } \\
\text { 1-year local recurrence rate (\%) }\end{array}$ & $57(91)$ & $13(93)$ & $5(71)$ \\
2-year local recurrence rate (\%) & 14 & 0 & $20 \%$ \\
1-year disease-free survival (\%) & 75 & 0 & $20 \%$ \\
2-year disease-free survival (\%) & 55 & 75 & 80 \\
1-year overall survival (\%) & 96 & 75 & 80 \\
2-year overall survival (\%) & 94 & 50 & 100 \\
\hline
\end{tabular}

data to be included in the oncologic analysis (Table 6). Median follow-up was 22 months (range 6-87). R0 resection rate for HCC, ICC, and GBC were $91 \%, 93 \%$, and $71 \%$, respectively. 2-year local recurrence rates for $\mathrm{HCC}$ and ICC were $14 \%, 0 \%$, and $20 \%$, respectively. 2-year disease-free survival for HCC, ICC, and GBC was $55 \%, 17 \%$, and $80 \%$, respectively. 2-year overall survival for HCC, ICC, and GBC was $94 \%, 50 \%$, and $100 \%$, respectively. 


\section{Discussion}

We describe our institutional experience of $225 \mathrm{RH}$, which to our knowledge is the largest reported cohort study to date and characterize the association between IWATE criteria and outcomes after RH. In this cohort, RH is shown to be safe and feasible, with an overall complication rate of $14 \%$ and a $4 \%$ open conversion rate. Oncologic outcomes for PHB malignancies were comparable to other published series with 2-year local recurrence rate of $14 \%, 55 \%$ 2-year diseasefree survival rate, and a 94\% 2-year overall survival rate for HCC [19].

The IWATE criteria were developed in 2014 during the Second International Consensus Conference on Laparoscopic Liver Resections held in Morioka, Japan, in the IWATE prefecture [14]. The criteria made minor modifications to the original Ban laparoscopic difficulty score [13], including segment 1 resections, differentiating segment $4 \mathrm{~A}$ from 4B, and accounting for the hand-assist laparoscopic or hybrid method. The IWATE criteria have been extensively validated in standard laparoscopic hepatectomy [20,21], and only recently applied to RH [22]. In our study, we found the criteria be associated with perioperative variables often observed with more challenging resections, including higher EBL, OR time, and LOS on both univariate and multivariable analyses. This classification system may represent an important tool for robotic liver surgeons to predict the difficulty of RH according to preoperative variables and to safely select cases for RH by skill level.

We observed a significant proportion of RH to be used for higher difficulty resections based on IWATE criteria, with $43 \%$ of RH performed for advanced- or expert-level resections during our initial institutional experience. In our series, we performed higher numbers of anatomic segmentectomies (43\%) and lower major anatomic hepatectomies (13\%) compared to other published minimally invasive series [21]. This reflects our institutional approach to favor parenchymalsparing approaches when possible. RH for these resections showed higher EBL, OR time, and complication rate compared to resections in other segments but achieved comparable $\mathrm{R} 0$ resection rates and LOS.

These data support the findings of several groups that have reported a unique advantage of the robotic surgical platform in performing parenchymal-sparing liver resections of the posterosuperior segments that are difficult to access via standard laparoscopy [10, 12, 23-25]. In contrast to performing a right hepatectomy laparoscopically for tumors located in the posterior segments, a parenchymal-sparing robotic approach to these segments is advantageous for maximally preserving future liver remnant. Sparing parenchyma is becoming increasingly important in cancer patients, particularly those with colorectal cancer metastases, who are living longer with more effective and hepatotoxic systemic chemotherapy regimens and often benefit from resection of intrahepatic recurrence [26, 27]. At our institution, the safe and effective adoption of $\mathrm{RH}$ for these difficult segmental resections supports extending the indication for RH and establishes it as a minimally invasive parenchymal-sparing alternative to major resection or conventional open minor resection when technically feasible. Examination and comparison of outcomes after RH with open and standard laparoscopic resection using propensity score matching at our institution are ongoing.

This study has several important limitations. First, this is a single center study limiting its generalizability and introducing institutional and surgeon bias for robotic technique. Furthermore, as a retrospective series using chart review, data collection was limited to information available in the electronic medical record. In regard to oncologic outcomes, as the University of Washington Medical Center is a tertiary care referral health system that serves the Washington, Wyoming, Alaska, Montana, and Idaho (WWAMI) region, many patients in this series who came to our center for their initial consultation and subsequent operation were lost to followup when they returned to their local oncology providers for ongoing care; therefore, oncologic outcomes such as recurrence and death were censored. Given that our multidisciplinary clinic provides comprehensive specialty care for liver tumors and requests follow-up information on surveillance imaging performed by our referring providers, we do expect that most cases of recurrence were captured in our review of outside records; conversely, patients who enjoyed a good response likely had no reason to follow-up with our clinic, and providers were more likely to contact us back regarding patients who had developed recurrence than those that had not. This reporting bias may negatively influence our results to show worse oncologic outcomes than truly occurred.

In conclusion, in our series of $225 \mathrm{RH}$, we characterized the association between the IWATE criteria and important operative outcomes, highlighting its utility in predicting resection difficulty and assisting in appropriate patient selection for RH. Our series also highlight the utility of RH for difficult hepatic resections, particularly parenchymal-sparing resections in the posterosuperior segments, extending the indication of minimally invasive hepatectomy in experienced hands and potentially offering select patients an alternative to open hepatectomy or less definitive alternative liverdirected therapies.

\section{Acknowledgements None.}

\section{Compliance with ethical standards}

Disclosures James O. Park received $<\$ 10,000$ educational grant from Intuitive Surgical Inc. for educational projects unrelated to this original 
research. Kevin P. Labadie MD, David J. Droullard MD, Alex W. Lois MD, Sara K. Daniel MD, Kathryn E. McNevin MD, Jaqueline Valdez Gonzalez BS, Yongwoo D. Seo MD, Kevin M. Sullivan MD, Kyle S. Bilodeau MD, Alan F. Utria MD, John Calhoun, Jonathan G. Sham MD, Venu G. Pillarisetty MD, and Raymond S. Yeung MD have no relevant conflicts of interest to disclose.

Open Access This article is licensed under a Creative Commons Attribution 4.0 International License, which permits use, sharing, adaptation, distribution and reproduction in any medium or format, as long as you give appropriate credit to the original author(s) and the source, provide a link to the Creative Commons licence, and indicate if changes were made. The images or other third party material in this article are included in the article's Creative Commons licence, unless indicated otherwise in a credit line to the material. If material is not included in the article's Creative Commons licence and your intended use is not permitted by statutory regulation or exceeds the permitted use, you will need to obtain permission directly from the copyright holder. To view a copy of this licence, visit http://creativecommons.org/licenses/by/4.0/.

\section{References}

1. Giulianotti PC, Bianco FM, Daskalaki D, Gonzalez-Ciccarelli LF, Kim J, Benedetti E (2016) Robotic liver surgery: technical aspects and review of the literature. Hepatobiliary Surg Nutr 5:311-321

2. Beard RE, Khan S, Troisi RI, Montalti R, Vanlander A, Fong Y, Kingham TP, Boerner T, Berber E, Kahramangil B, Buell JF, Martinie JB, Vrochides D, Shen C, Molinari M, Geller DA, Tsung A (2020) Long-term and oncologic outcomes of robotic versus laparoscopic liver resection for metastatic colorectal cancer: a multicenter, propensity score matching analysis. World J Surg 44:887-895

3. Berber E, Akyildiz HY, Aucejo F, Gunasekaran G, Chalikonda S, Fung J (2010) Robotic versus laparoscopic resection of liver tumours. Hpb 12:583-586

4. Chong CCN, Lok HT, Fung AKY, Fong AKW, Cheung YS, Wong J, Lee KF, Lai PBS (2019) Robotic versus laparoscopic hepatectomy: application of the difficulty scoring system. Surg Endosc $1-7$

5. Nota CL, Rinkes IHB, Molenaar IQ, Santvoort HCV, Fong Y, Hagendoorn J (2016) Robot-assisted laparoscopic liver resection: a systematic review and pooled analysis of minor and major hepatectomies. Hpb 18:113-120

6. Morise Z, Wakabayashi G (2017) First quarter century of laparoscopic liver resection. World J Gastroenterol 23:3581-3588

7. Liu R, Wakabayashi G, Kim H-J, Choi G-H, Yiengpruksawan A, Fong Y, He J, Boggi U, Troisi RI, Efanov M, Azoulay D, Panaro F, Pessaux P, Wang X-Y, Zhu J-Y, Zhang S-G, Sun C-D, Wu Z, Tao K-S, Yang K-H, Fan J, Chen X-P (2019) International consensus statement on robotic hepatectomy surgery in 2018 . World J Gastroenterol 25:1432-1444

8. Sucandy I, Giovannetti A, Ross S, Rosemurgy A (2020) Institutional first 100 case experience and outcomes of robotic hepatectomy for liver tumors. Am Surg 86:200-207

9. Sucandy I, Luberice K, Lippert T, Castro M, Krill E, Ross S, Rosemurgy A (2020) Robotic major hepatectomy: an institutional experience and clinical outcomes. Ann Surg Oncol 27:4970-4979

10. Casciola L, Patriti A, Ceccarelli G, Bartoli A, Ceribelli C, Spaziani A (2011) Robot-assisted parenchymal-sparing liver surgery including lesions located in the posterosuperior segments. Surg Endosc 25:3815-3824

11. Leung U, Fong Y (2014) Robotic liver surgery. Hepatobiliary Surg Nutrition 3:288-294
12. Nota CL, Woo Y, Raoof M, Boerner T, Molenaar IQ, Choi GH, Kingham TP, Latorre K, Rinkes IHMB, Hagendoorn J, Fong Y (2019) Robotic versus open minor liver resections of the posterosuperior segments: a multinational, propensity score-matched study. Ann Surg Oncol 26:583-590

13. Ban D, Tanabe M, Ito H, Otsuka Y, Nitta H, Abe Y, Hasegawa Y, Katagiri T, Takagi C, Itano O, Kaneko H, Wakabayashi G (2014) A novel difficulty scoring system for laparoscopic liver resection. J Hepato-bil-pan Sci 21:745-753

14. Wakabayashi G (2016) What has changed after the Morioka consensus conference 2014 on laparoscopic liver resection? Hepatobiliary Surg Nutr 5:281-289

15. Couinaud C (1954) Liver lobes and segments: notes on the anatomical architecture and surgery of the liver. Presse Med 62:709-712

16. Association TCotIH-P-B, Strasberg SM, Belghiti J, Clavien PA, Gadzijev E, Garden JO, Lau WY, Makuuchi M, Strong RW (2000) The Brisbane 2000 Terminology of liver anatomy and resections. Hpb 2:333-339

17. Makuuchi M, Hasegawa H, Yamazaki S (1985) Ultrasonically guided subsegmentectomy. Surg Gynecol Obstet 161:346-350

18. Yoshida H, Katayose Y, Rikiyama T, Motoi F, Onogawa T, Egawa S, Unno M (2012) Segmentectomy of the liver. J Hepato-bil-pan Sci 19:67-71

19. Khan S, Beard RE, Kingham PT, Fong Y, Boerner T, Martinie JB, Vrochides D, Buell JF, Berber E, Kahramangil B, Troisi RI, Vanlander A, Molinari M, Tsung A (2018) Long-term oncologic outcomes following robotic liver resections for primary hepatobiliary malignancies: a multicenter study. Ann Surg Oncol 25:2652-2660

20. Krenzien F, Wabitsch S, Haber P, Kamali C, Brunnbauer P, Benzing C, Atanasov G, Wakabayashi G, Ollinger R, Pratschke J, Schmelzle M (2018) Validity of the Iwate criteria for patients with hepatocellular carcinoma undergoing minimally invasive liver resection. J Hepatobiliary Pancreat Sci 25:403-411

21. Tanaka S, Kawaguchi Y, Kubo S, Kanazawa A, Takeda Y, Hirokawa F, Nitta H, Nakajima T, Kaizu T, Kaibori M, Kojima T, Otsuka Y, Fuks D, Hasegawa K, Kokudo N, Kaneko H, Gayet B, Wakabayashi G (2019) Validation of index-based IWATE criteria as an improved difficulty scoring system for laparoscopic liver resection. Surgery 165:731-740

22. Luberice K, Sucandy I, Modasi A, Castro M, Krill E, Ross S, Rosemurgy A (2020) Applying IWATE criteria to robotic hepatectomy: is there a "robotic effect"? HPB (Oxford) 22:S85

23. Troisi RI, Patriti A, Montalti R, Casciola L (2013) Robot assistance in liver surgery: a real advantage over a fully laparoscopic approach? Results of a comparative bi-institutional analysis. Int J Medical Robotics Comput Assisted Surg 9:160-166

24. Patriti A, Cipriani F, Ratti F, Bartoli A, Ceccarelli G, Casciola L, Aldrighetti L (2014) Robot-assisted versus open liver resection in the right posterior section. Jsls J Soc Laparoendosc Surg 18(e2014):00040

25. Cho JY, Han H-S, Yoon Y-S, Shin S-H (2008) Feasibility of laparoscopic liver resection for tumors located in the posterosuperior segments of the liver, with a special reference to overcoming current limitations on tumor location. Surgery 144:32-38

26. Alvarez FA, Sanchez Claria R, Oggero S, de Santibanes E (2016) Parenchymal-sparing liver surgery in patients with colorectal carcinoma liver metastases. World J Gastrointest Surg 8:407-423

27. Moris D, Dimitroulis D, Vernadakis S, Papalampros A, Spartalis E, Petrou A, Pawlik TM, Felekouras E (2017) Parenchymalsparing hepatectomy as the new doctrine in the treatment of liver-metastatic colorectal disease: beyond oncological outcomes. Anticancer Res 37:9-14

Publisher's Note Springer Nature remains neutral with regard to jurisdictional claims in published maps and institutional affiliations. 